\title{
The Impact of Writing Self-Assessment and Peer Assessment on Iranian EFL Learners' Autonomy and Metacognitive Awareness
}

\author{
Maryam Ebrahimi $\mathbb{D}^{1},{ }^{1}$ Siros Izadpanah $\left(\mathbb{D},{ }^{1}\right.$ and Ehsan Namaziandost $\mathbb{D}^{2}$ \\ ${ }^{1}$ Department of English Language Teaching, Zanjan Branch, Islamic Azad University Zanjan, Zanjan, Iran \\ ${ }^{2}$ Department of English, Shahrekord Branch, Islamic Azad University, Shahrekord, Iran \\ Correspondence should be addressed to Siros Izadpanah; cyrosizadpanah@yahoo.com
}

Received 17 July 2021; Revised 6 September 2021; Accepted 17 September 2021; Published 29 October 2021

Academic Editor: Enrique Palou

Copyright (c) 2021 Maryam Ebrahimi et al. This is an open access article distributed under the Creative Commons Attribution License, which permits unrestricted use, distribution, and reproduction in any medium, provided the original work is properly cited.

\begin{abstract}
One of the most significant current discussions in writing is self-assessment and peer assessment. This study aimed to investigate the impact of writing self-assessment and peer assessment on autonomy and metacognitive awareness of Iranian EFL learners. One hundred and twenty participants were selected using convenience sampling. Four instruments were used in this test: (1) Nelson placement test; (2) Metacognitive Awareness Inventory (MAI); (3) Zhang and Li's autonomy questionnaire; and (4) rubric. A quasiexperimental design was used in this study. They were divided into two experimental groups, self-assessment $(N=40)$ and peer assessment $(N=40)$, and one control group $(N=40)$. Collected data were tested and compared using covariance analysis (ANCOVA). Results from the tests indicated that both self-assessment and peer assessment are effective ways to improve autonomy and metacognition awareness of EFL learners in the completion of writing tasks. Findings also showed that selfassessment was more effective than peer assessment and the results showed that the types of assessments increased the learners' knowledge in the writing, teaching, lexicography, spelling, grammar, and similar models and were significantly effective in developing their writing skills. The findings of the present research study might have some implications for researchers, instructors, language teachers, and language learners.
\end{abstract}

\section{Introduction}

Increasing research at the international level indicates that holders of appropriate writing skills have a special position compared to their peers $[1,2]$. At the same time, writing is the most difficult skill in learning a second language and based on the natural order hypothesis is the last skill to be learned [3]. This skill is known as a complex cognitive activity that requires careful thinking, knowledge, and concentration and is not just the product of what the mind knows and can do in a given moment. Since the 1980s, many prominent thinkers and researchers have advocated a shift from education to learning. Assessment has played a key role in this regard. Assessment is seen as a process in which information is gathered and discussed from a variety of sources and used to improve subsequent learning to deepen learners' understanding of what they know and can do $[4,5]$.
In the assessment process, the learner is the focus, and in the assessment, not only is the learning process monitored, but also its improvement is done. Assessment can also increase the motivation of learners and be effective in identifying the strengths and weaknesses of learners by the teacher [6].

One of the most significant current discussions in the field of teaching and learning English as a Second/Foreign Language (ESL/EFL) is how to help learners to take responsibility for their own learning and how to use their knowledge to be independent in both learning and evaluation $[7,8]$. It has been said that learner autonomy can be considered one of the elements in language teaching [9]. On the other side, there has been an increasing interest in alternative assessment approaches such as self-assessment and peer assessment which require direct involvement of the learners in learning and assessing language skills [10-12]. Finding ways to know how a learner's autonomy and metacognitive assessment can be 
enhanced and how self-assessment and peer assessment may increase learner autonomy and metacognitive awareness is an undeniable part of language learning. Recent developments in peer-assessment and self-assessment use have heightened the need for investigation of their effect on autonomy and metacognitive awareness of EFL learners' written production. Writing collaboratively and giving feedback on peer's scripts and reflection on one's own writing help learners engage in group activities or improve individualization in learning $[11,13,14]$.

Autonomy is taking responsibility for one's own learning. Most scholars and educators believe that the integration of autonomy is necessary in language learning in order to assist learners to learn a language [5, 13, 15-19]. It is believed that metacognition is effective in language learning successfully $[20,21]$. The question of how to improve learners' autonomy and metacognitive awareness is a controversial issue that has been addressed in a few studies. In most of the studies, it has been investigated how autonomy and metacognition improve language learning in general and language skills in specific [6, 22-25]. All in all, reviewing the literature so far indicates that the impact of writing selfassessment and peer assessment on Iranian EFL learners' autonomy and metacognitive awareness has not received as much attention as warranted. Moreover, rare studies, if any, have been done in this regard in the Iranian context. Thus, to cover these gaps, the researchers aim to explore if writing self-assessment and peer assessment have any role in Iranian EFL learners' autonomy and metacognitive awareness.

With regard to the Iranian EFL context, a number of empirical studies have been carried out to investigate the impact of self-assessment and peer-assessment activities on L2 writing competencies ([26-31], to name a few). However, the effects of these two types of alternative assessment on writing autonomy and metacognitive have remained underresearched to shed more light on it.

The findings of this study should make an important contribution to the field of teaching and language learning. It is expected that this research would help the language teachers to become more aware of various types of assessment, in order to help and lead the learners toward autonomy and metacognitive awareness and learning in a maintained engaged and motivating atmosphere.

The aim of this study was to examine the following research questions:

(1) Does self-assessment in writing have any significant effect on Iranian EFL learners' autonomy in an EFL context?

(2) Does self-assessment in writing have any significant effect on Iranian EFL learners' metacognitive awareness in an EFL context?

(3) Does peer assessment in writing have any significant effect on Iranian EFL learners' autonomy in an EFL context?

(4) Does peer assessment in writing have any significant effect on Iranian EFL learners' metacognitive awareness in an EFL context?

\section{Review of Literature}

2.1. Peer Assessment. Peer assessment as one of the alternative assessment procedures has been recognized as activities, which are used by language learners in order to assess each other's performance [32]. In another definition, it is suggested that peer assessment is "an arrangement for peers to consider the level, value, worth, quality or successfulness of the products or outcomes of learning of others of similar status" [8].

According to Karami and Rezaei [14], peer assessment is one of the main procedures of alternative assessment which pedagogically improves learning and increases creativity, responsibility, and higher thinking of learners. They also defined peer assessment as "an educational arrangement where students judge a peers' performance quantitatively and/or qualitatively and which stimulates students to reflect, discuss and collaborate" (as cited in [14]; p. 95).

Liu and Carless [33] defined peer assessment and peer feedback as a communication process through which learners enter into dialogues related to performance and standards. Peer assessment is defined as students grading the work or performance of their peers using relevant criteria [34]. So, our distinction between the two terms is that peer feedback is primarily about rich detailed comments but without formal grades, while peer assessment denotes grading (irrespective of whether comments are also included). Whether grades are awarded or not, the emphasis is on standards and how peer interaction can lead to enhanced understandings and improved learning.

2.2. Self-Assessment. Self-assessment is conceptualized as a procedure by which the learners themselves evaluate their skills and knowledge. The main merit attributed to selfassessment is that it encourages students to get more actively engaged in the educational process by requiring them to reflect on their own performances and by encouraging them to take greater responsibility for goal setting and decisionmaking about their own learning. Richards and Schmidt [35] interpreted self-assessment as “checking one's own performance on a language learning task after it has been completed or checking one's own success in using a language. Self-evaluation is an example of a metacognitive strategy in language learning."

Oscarson and Apelgren [35] argued that self-assessment is a way to help learners become aware of their own progress and achievement and better understand and learn instruction. Birjandi and Siyyari [36] reported that self-assessment takes less time to be conducted in language classrooms and engages learners in the assessment process which results in higher learning and motivation. Liu and Brantmeier [13] and Plakans [37] also emphasized that self-assessment acts as a metacognitive tool and helps learners reflect on their own learning, make learning decisions, and set learning goals. Similarly, Baleghizadeh and Masoun [10] confirmed that self-assessment raises awareness and self-reflection among learners and helps them monitor their own learning in order to improve goal orientation and improve learner autonomy. 
2.3. Metacognitive Awareness. Metacognition is one of the factors in language teaching which has been recognized to help learners to act independently [38]. Cotterall and Murray [39] stated that students usually lack the required metacognitive skills to manage and monitor their learning independently. In one definition by Antonietti and Mancini [40], they explained that metacognition is knowledge which individuals know about the performance and function of their own cognitive skills processes. Similarly, Schraw and Dennison [40] clarified that metacognitive awareness is "knowledge concerning one's own cognitive processes and products, or anything related to them" (as cited in [39]; p. 35). It is also believed that metacognitive awareness is a set of mental strategies and procedures which learners utilize to organize their learning [41]. In addition, Goctu [41] emphasized that metacognitive strategies include skills for planning, monitoring, evaluating, controlling, and understanding cognitive strategies such as problem-solving. Metacognition is defined as a special type of awareness each individual possesses to manage and control information. Moreover, metacognitive skills and strategies help learners engage in the learning process, reflect on their learning and performance, and try to perform better [42]. Metacognitive experiences are affective and cognitive experiences related to the learning process. The experiences and activities which individuals do to reach their learning goals are important elements. Knowing and using these variables appropriately are useful for being successful in achieving goals.

Azizi et al. [23] explained that metacognitive awareness help learners engage in the learning process actively, monitor and direct their own learning, and finally find and decide on new ways for better learning and improving what they have learned. Farahian [43] discussed that metacognition is necessary for self-regulation in second language learning. As such, metacognition provides an opportunity to plan to learn, monitor the learning process, and organize and regulate the learning process and completion of it. Rahimi and Katal [44] also confirmed that metacognitive awareness is an effective way for learners to regulate their own learning through reflection and thinking critically on tasks they should do, accomplish what tasks require them to do, and find ways to accomplish the task. In line with the above studies, Doğan and Tuncer [45] illustrated that metacognitive awareness plays a key role in the learning process of language learners since it helps learners evaluate what they are learning, what they need to learn, what ways improve and accelerate their learning, and how to find these ways for progress in learning. However, learners' awareness of metacognition is not enough to direct them toward success in language learning. It is required that teachers and instructors teach learners how to use metacognitive strategies appropriately $[45,46]$.

2.4. Self-Assessment and Autonomy. Gholami [47] investigated the effect of self-assessment along with peer assessment on the learner autonomy of EFL learners in Iran. He conducted PET test to homogenize the participants. Also, he mentioned that students were trained to assess their language proficiency and their peers (homework, workbook, and being active in class). According to what the researcher had stated, the criteria used for evaluating the language proficiency of self and peers are not crystal clear. Overall, it is not mentioned that learners assess themselves and peers exactly based on what benchmarks. Another factor is that the researcher mentions the effect of self-assessment accompanied with peer assessment, while reported results are just based on self-assessment. Participants of the study were 25 in the control group and 24 in the experimental group aged from 18 to 35 . The number of participants was not enough to generalize the results, especially in a questionnaire study. The findings of the questionnaire study showed that selfassessment had a positive impact on learner autonomy in general but in some components, there was not any significant difference between the experimental group and the control group. Since this study compared the effect of selfassessment on the autonomy of learners and language proficiency, it is different from the purpose of the present study which just focused on the learner autonomy in writing skills.

Liu and Brantmeier [13] examined the effect of selfassessment on writing ability of 106 (56 males and 50 females) Chinese English learners aged 12-14. A reading comprehension test and a writing task were used to measure learners' language skills. A writing task was used, and participants were asked to describe a picture. Regarding selfassessment, a survey including 14 writing self-assessment items was designed and participants rated their writing ability on a Likert scale. Findings revealed that young learners are able to self-assess their writing skills appropriately. This study just focused on the self-assessment and writing accuracy of young learners and it cannot answer the questions of the present study on autonomy and metacognition.

2.5. Self-Assessment and Metacognitive Awareness. It is believed that metacognition is effective in language learning successfully [20]. In her study, Siegesmund [20] argued that self-assessment is a reflection tool. In fact, learners use some criteria to assess their own performance and think critically about their learning process. Therefore, self-assessment is an effective way to increase metacognitive awareness and learn more metacognitive strategies to better learn in language learning.

Thirtle [48] selected an intact class of students to investigate the effect of self-assessment on metacognitive awareness of language learners. Participants were 13 females and two males aging 17-19. Questionnaires were distributed among participants as pretest and posttest. Also, semistructured interviews were used to triangulate the study. Students received self-assessment instruction and were asked to assess their own performance. Moreover, participants were given feedback in order to set goals for their future writing tasks. Results of the questionnaire study confirmed the positive effect of self-assessment on metacognitive awareness increase. Participants in posttest indicated more attention and reflection on their tasks. Interview 
results showed that learners found feedback giving an effective way to improve their writing essays. Results of this study, despite its triangulation method, cannot be generalized due to the few numbers of participants and convenient sampling method.

2.6. Peer Assessment and Autonomy. One study focusing on speaking skills studied the role of self-assessment and peer assessment on learner autonomy. Ashraf and Mahdinezhad [15] investigated the effect of self-assessment (24 students as the control group) and peer assessment (24 students as the experimental group) on the speaking and autonomy of EFL learners. The focus of this study is different from the present study regarding that the present study targets autonomy in writing skills. In addition, the number of participants does not seem to be sufficient to be generalized into a larger community.

In a comparative study by Birjandi and Siyyari [36], they indicated that self-assessment and peer assessment are effective tools to improve writing and accuracy among EFL learners. This study investigated the self- and peer-assessment effect comparatively on the writing and accuracy of EFL learners. Results of it cannot answer the research questions of the present study regarding the impact of self-assessment and peer assessment on the writing autonomy of EFL learners.

de Brusa and Harutyunyan [16] examined the impact of peer assessment on the academic writing of English learners. 32 male students and 36 female students from different majors participated in the study. They have 10-hour English classes weekly. This study revealed valuable results of peer assessment on writing skills. However, it cannot meet the purpose of the present study regarding autonomy and metacognition.

Suludere [49] in an online environment investigated the relationship between peer assessment and learner autonomy on writing skills. Data was collected using 2 questionnaires and interview from 14 students attending a writing course as EFL learners. Students were invited to join an online forum. In some training sessions, they were taught how to give feedback to their peers. They were asked to write essays online and at the same time give feedback to peers' essays. A questionnaire of peer feedback was distributed among students before and after the study. Another questionnaire was related to the familiarity of students with the Internet and online forums. The questionnaire of peer feedback included items related to learner autonomy. Overall, items included learners' awareness of their own learning, taking responsibility for their own learning, active engagement in the learning process, and evaluation of one's own learning. Generally, results confirmed that peer assessment had a positive impact on improvement of learner autonomy. However, in the case of this study, the effect of online learning should be considered, as well.

\subsection{Peer Assessment and Metacognitive Awareness.} Regarding the effect of peer assessment on the metacognitive awareness in writing skills, there is scarce related literature. However, there are some studies that investigated the effect of metacognition on the writing skills of English learners. In the following, some of these studies are discussed.

Azizi et al. [23] conducted a study to examine the relationship between metacognitive awareness and writing proficiency of 30 Iranian EFL learners. Participants (all female learners aged from 20 to 26) were asked to complete questionnaires and writing tests. A metacognitive awareness questionnaire including four main categories, planning, evaluation, monitoring, and self-awareness writing strategies, was constructed. At the start, participants filled in the metacognitive questionnaire. During treatment sessions, they were asked to write essays. Their essays were corrected by their teacher based on grammar and vocabulary accuracy. According to the results of the questionnaire, it was reported that monitoring was the highest strategy used by learners while self-awareness was the lowest strategy. However, this discrepancy was not so significant among the four categories of metacognitive awareness. Regarding the relationship between writing performance and metacognitive awareness, it was found that just evaluation was the highest strategy effective in writing. In this study, the method used for examining the effect of metacognitive awareness on writing performance is not clarified. Moreover, there was not any posttest to show the effect of metacognitive strategies on the writing of learners. Furthermore, participants are only females who had been selected conveniently.

In another study, Al-Jarrah et al. [22] examined the effect of metacognition on the writing skills of 44 secondary school students in Jordan. Researchers used pretest, posttest, and delayed posttest to examine the metacognition effect. In the experimental group, metacognitive strategies were taught but the control group received routing instruction of writing. After five weeks of treatment, a posttest was administered. Then another delayed posttest was run at week twelve. Results of comparing means of control and experimental groups pretest showed no significant difference. However, it was found that there is a significant difference between the results of pretest and posttest. Also, delayed posttest indicated a significant difference. Overall, it was found that metacognitive strategies' instruction is an effective way in writing improvement of English learners. The focus of this study was on the metacognitive strategies and writing. So, the results of it cannot fulfill the purpose of the present study.

\section{Method}

3.1. Design. A quasiexperimental design was used in this study since randomization was not applied in the assignment of participants. In fact, participants included classes, which were selected using convenience sampling. The participants participated in the pretest and posttest. Independent variables of the research were self-assessment and peer assessment. Dependent variables were autonomy and metacognitive awareness.

3.2. Participants. Participants were selected from five classes using convenience sampling. Participants included $120 \mathrm{EFL}$ learners taking English courses in ACECR (Academic 
Center for Education, Culture, and Research). The participants were chosen among the learners who were at the intermediate level based on the institute's placement test. However, to assure the homogeneity of the participants for the present study, they were selected according to the result of the Nelson placement test [50]. The participants were aged from 18 to 36. The reason for choosing this level was that this study was difficult for lower level and at the same time it was easier for advanced learners. They were assigned to two experimental groups and one control group. Each group consisted of 40 learners. In the pilot study, 30 language learners were selected for calculating reliability by using Cronbach's alpha.

3.3. Instruments. Four instruments were used in the present study. Nelson placement test 200 A [50] was used as a standardized language proficiency test to check the homogeneity of participants' proficiency levels. It included 50 multiple-choice items on cloze tests, structure, and vocabulary. The second instrument was the Metacognitive Awareness Inventory (MAI), developed and revised by Terlecki and McMahon [51]. It was used to assess the metacognitive awareness of the participants. Knowledge of cognition included three subcategories: declarative knowledge, procedural knowledge, and conditional knowledge. The third instrument was Zhang and Li's [52] autonomy questionnaire, which was used to evaluate learner's autonomy. The fourth instrument was rubric, which was an attempt to communicate expectations of quality around a task. In many cases, scoring rubrics are used to delineate consistent criteria for grading. Because the criteria are public, a scoring rubric allows teachers and students alike to evaluate criteria, which can be complex and subjective.

These instruments were used in the present study. It included 50 multiple-choice items on cloze tests, structure, and vocabulary.

The next instrument was the Metacognitive Awareness Inventory (MAI), developed by Schraw and Dennison [40] was used to assess the metacognitive awareness of the participants. It includes 52 items, which assess various facets of metacognition. Items of MAI are under two categories: "knowledge of cognition" and "regulation of cognition." Seventeen items of the MAI measure knowledge of cognition, and the remaining thirty-five items assess the regulation of cognition. Knowledge of cognition included three subcategories as follows:

3.4. Declarative Knowledge. The student's actual knowledge before becoming able to process or use critical thinking about the subject, they must be aware of their skills, intellectual resources, and abilities as a learner. Students can get knowledge through presentations, demonstrations, and discussions.

3.5. Procedural Knowledge. Using knowledge to complete a method or process and knowledge of how to implement learning methods (e.g., strategies) requires that students be aware of the process as well as when to use the process in different situations. They can explore, learn collaboratively, and solve problems.

3.6. Conditional Knowledge. Determining under what conditions specific processes or skills should be transferred, knowledge of when and why to use learning methods, and application of declarative and procedural knowledge with specific conditions provided, students can acquire knowledge through simulation [40].

On the other hand, regulation of cognition included five subcategories:

(1) Planning

Planning, goal setting, and allocating resources prior to learning.

(2) Information management strategies

Skills and strategy sequences used to process information more efficiently (e.g., organizing, elaborating, summarizing, and selective focusing).

(3) Comprehension monitoring

Assessment of one's learning or strategy use.

(4) Debugging strategies

Strategies to correct comprehension and performance errors.

(5) Evaluation

Analysis of performance and strategy effectiveness after a learning episode [40].

The third instrument was Zhang and Li's [52] autonomy questionnaire which was used to evaluate learner's autonomy. The questionnaire has two parts. The first part contains 11 items and the second 10, totally 21 items. The first 11 items have five options in the Likert scale from never to always (A: never, B: rarely, C: sometimes, D: often, and E: always). The second part of the questionnaire is in multiple-choice format. The participants chose the closest answer to their beliefs and their attitudes or ideas. The participants' choices in the questionnaire were the scores from A to $\mathrm{E}$ that are, respectively, 1, 2, 3, 4, and 5. All the items of this instrument are directional and therefore, the range of scores is basically from 21 to 105 .

3.7. Procedure. Two questionnaires as a pretest and posttest were utilized to measure the participants' metacognitive awareness and learner autonomy before and after the main treatment. The tests were piloted to ensure their reliability. To measure the reliability of questionnaires, they were given to 30 individuals. First, 120 participants from language learners of intermediate classes in two language institutes in Zanjan, Iran, were selected. The participants were divided into two equal experimental groups ( $N=40$ in each group) and one control group $(N=40)$. One experimental group was taught based on the self-assessment instruction in writing skills using TOEFL for Instruction. Another 
experimental group was taught through peer-assessment instruction writing skills. In other words, both groups' writing instruction was conducted according to TOEFL Independent and Integrated Writing Rubrics. Let us consider the rubrics for the Writing Tasks in TOEFL (there are two writing tasks, the Integrated Writing and the Independent Writing). Each task in the TOEFL Writing section was given a score from a scale of $0-5$ only and the marks for these two tasks were converted to $0-30$ marks to give us the overall marks for the Writing section. In order to get the highest score of 5 for the Independent Writing, we need to do the following:

(i) Address the topic and task.

(ii) Organize and develop our essay well, with appropriate explanations, examples, and details.

(iii) Show unity, progression, and coherence in our essay.

(iv) Show consistent use of language, with syntactic variety, appropriate word choice, and idiomaticity.

(v) Have no or minor lexical and grammatical errors. Prior to the treatment, three groups took the pretest (filling in MAI and autonomy questionnaires). Then, following eight sessions of treatment on selfassessment, and peer assessment, the posttest was administered.

3.8. Data Analysis. In order to respond to research questions, the data were analyzed, and to ensure the normality of the distribution, descriptive statistics analysis was run. To examine the differences among the mean scores on the pretests and posttests, Covariance Analysis (ANCOVA) was conducted.

\section{Results}

To review and analyze the data through the ANCOVA test, the defaults of the ANCOVA test are first examined.

4.1. The Normality of the Data. The results of the Kolmogorov-Smirnov test showed that the level of significance of the research variables in all peer-assessment, self-assessment, and control groups is normal (Sig. > 0.05).

4.2. Homogeneity Test of Variances. The results showed that the homogeneity of variance between the control and peerassessment pretest groups as well as the control and selfassessment pretest groups is accepted through the Loon test (Sig. > 0.05).

4.3. Homogeneity of Regression Slopes. The results showed that the regression homogeneity test between the covariate variable and the independent variable is accepted.
4.3.1. The Linearity of Correlation between Covariate and Independent Variables. The linearity hypothesis of a correlation between covariate and peer-assessment variables is accepted (Sig. <0.05).

(1) Test of Research Hypotheses. The first hypothesis was that self-assessment in writing does not have any significant effect on Iranian EFL learners' autonomy in an EFL context. To test the hypothesis, the covariance analysis was used. The results of the test are shown in Table 1.

As it can be seen in Table 1, F equals 20.545. Since Sig. $\leq 0.001$, it is concluded that it is significant, and the first null hypothesis is rejected. Therefore, there is a significant difference between the pretest and posttest scores. As was seen before in Table 1, the means of autonomy scores in the self-assessment of the control group in pretest and posttest were 20.03 and 24.20, respectively, while the means of autonomy scores in the self-assessment pretest and posttest were 23.48 and 31.13. Regarding the differences between pretest and posttests, the effect of self-assessment on the autonomy of learners is confirmed.

The second hypothesis stated that self-assessment in writing does not have any significant effect on Iranian EFL learners' autonomy in an EFL context. To test the hypothesis, covariance analysis was used. The results are shown in Table 2.

As Table 2 showed, the value of $F$ equals 108.90 and since Sig. $\leq 0.01$, it can be said that it is significant at 0.05 level. Therefore, the second null hypothesis is rejected and it can be concluded that there is a significant difference between the means of groups in the pretest and posttest. Regarding self-assessment in the control group, it was seen that the mean of the pretest was 38.98 and the mean of the posttest was 45.55 (Table 2). In addition, the mean of pretest in the experimental self-assessment group was 45.65 and the posttest of the same group was 60.80. According to the significant differences between pretest and posttest groups, it can be concluded that self-assessment influences learners' metacognitive awareness positively.

Self-assessment has a significant effect on metacognitive control in writing Iranian foreign language learners. The analysis of covariance has been used to test the above hypothesis. As noted, the necessary hypothesis for the analysis of covariance has been investigated and these hypotheses are established. The results of covariance analysis are recorded in the following tables.

As it can be seen in Table 3, the value of $\mathrm{F}$ in the analysis of covariance for the metacognitive control variable of selfassessment students is 132.81, and considering that Sig. $\leq 0.001$, it is significant at the level of 0.05 and the hypothesis of the ineffectiveness of its method assessment is rejected. Thus, it can be concluded that the mean of the two groups in the posttest is significantly different from each other after adjusting the pretest scores. As can be seen in Table 3, the average metacognitive awareness of students with the self-assessment method was 76.08 in the pretest control group and was 97.73 in the posttest, while the average metacognitive control of students was 81,35 in the pretest group and 122.58 in the posttest. Due to the 
TABLE 1: Results of covariance for autonomy variable in self-assessment group.

\begin{tabular}{lcccc}
\hline & Variable & Mean & Std. deviation & $F$ \\
\hline \multirow{2}{*}{ Experiment self-assessment group } & Autonomy pre & 23.48 & 4.37 & \\
\multirow{2}{*}{ Control group } & Autonomy post & 31.13 & 6.31 & \multirow{2}{*}{0.56} \\
& Autonomy pre & 20.03 & 6.07 & 0.001 \\
& Autonomy post & 24.20 & 4.86 & \\
\hline
\end{tabular}

TABLE 2: Results of covariance for metacognitive knowledge variable in self-assessment group.

\begin{tabular}{lcccc}
\hline & Variable & Mean & Std. deviation & $F$ \\
Experiment self-assessment group & Metacognitive awareness pre & 42.65 & 7.96 & \\
\multirow{2}{*}{ Control group } & Metacognitive awareness post & 60.80 & 4.43 & 108.90 \\
& Metacognitive awareness pre & 38.98 & 8.65 & 0.01 \\
& Metacognitive awareness post & 45.55 & 8.04 & \\
\hline
\end{tabular}

TABLE 3: Results of covariance analysis for the metacognitive control variable of self-assessment students.

\begin{tabular}{lcccc}
\hline & Variable & Mean & Std. deviation & $F$ \\
\hline \multirow{2}{*}{ Experiment self-assessment group } & Metacognitive control pre & 81.35 & 12.36 & \\
\multirow{2}{*}{ Control group } & Metacognitive control post & 122.58 & 7.76 & \multirow{2}{*}{132.81} \\
& Metacognitive control pre & 76.08 & 20.65 & 0.001 \\
& Metacognitive control post & 97.73 & 12.17 & \\
\hline
\end{tabular}

significant difference between posttest scores in the control and experimental groups, it is concluded that by eliminating the pretest cotest factor, the self-assessment effect increases students' metacognitive awareness.

The third hypothesis stated that peer assessment in writing does not have any significant effect on Iranian EFL learners' autonomy in an EFL context. Similarly, covariance analysis was used to test this hypothesis. The results of the test are displayed in Table 4.

In Table 4, as can be seen, the value of $\mathrm{F}$ is 23.47 and since Sig. $\leq 0.001$, it is stated that there is a significant difference between pretest and posttest scores. Therefore, the third null hypothesis is rejected and it can be concluded that peer assessment has a positive impact on autonomy. Also, it was seen (Table 4) that the means of the scores of learners' autonomy in peer-assessment control group pretest and posttest were 20.03 and 24.20 , respectively. In addition, the means of scores of learners' autonomy in peer-assessment experimental group pretest and posttest were 22.93 and 31.45, respectively. Considering the mean differences in pretests and posttests, it can be concluded that peer assessment can increase the autonomy of learners in their writing performance.

The last and fourth hypotheses stated that peer assessment in writing does not have any significant effect on Iranian EFL learners' metacognitive awareness in an EFL context. Covariance analysis was used to test this hypothesis. Results related to this hypothesis are shown in Table 5.

As Table 5 depicts, the value of $F$ equals 136.78 and Sig. $\leq 0.001$. Thus, it can be said that there is a significant difference between posttest and pretest mean scores which leads to the rejection of the null hypothesis. As it was already seen in Table 5, the mean scores of metacognitive awareness in the pretest and posttest of the peer-assessment control group were 38.98 and 45.55 , respectively, and the mean scores of learners in the pretest and posttest of the peerassessment experimental group were 40.33 and 60.88, respectively. Now, given the significant difference among the means of scores in pretest and posttest, it can be claimed that peer assessment can influence metacognitive awareness of language learners in their writing skills.

Peer assessment has a significant effect on metacognitive control in writing Iranian language learners. The analysis of covariance has been used to test the above hypothesis and the results of the analysis are recorded in the following tables.

As can be seen in Table 6, the value of $F$ in the analysis of covariance for the metacognitive control variable of peer assessment students is 146.23, and considering the Sig. $\leq 0.001$, the hypothesis of the ineffectiveness of peer method and assessment is rejected. As can be seen in Table 6, the mean score of metacognitive control with peer assessment method was 76.07 in the pretest control group and 97.73 in the posttest, while the mean score of metacognitive control of peer students was 77.128 in the pretest group and 122.40 in the posttest. Due to the significant difference between the scores in the posttest in the two control and experimental groups, it is concluded that, by eliminating the peer-to-peer coefficient of the test, the effect of peer assessment increases students' metacognitive control.

\section{Discussion}

Recent developments in assessment have heightened the need for studying writing self-assessment and peer assessment on Iranian EFL learners' autonomy and metacognitive awareness.

The first research question aimed to investigate the impact of writing self-assessment on the autonomy of learners in their writing performance. Results of the pretest 
TABLE 4: Results of covariance for autonomy variable in peer-assessment group.

\begin{tabular}{lcccc}
\hline & Variable & Mean & Std. deviation & $F$ \\
\hline \multirow{2}{*}{ Peer assessment students } & Autonomy pre & 22.93 & 4.13 & \\
\multirow{2}{*}{ Control group } & Autonomy post & 31.45 & 6.60 & \\
& Autonomy pre & 20.03 & 6.07 & 23.47 \\
& Autonomy post & 24.20 & 4.86 & 0.001 \\
\hline
\end{tabular}

TABLE 5: Results of covariance for metacognitive awareness variable in peer-assessment group.

\begin{tabular}{lcccc}
\hline & Variable & Mean & Std. deviation & $F$ \\
\hline \multirow{2}{*}{ Peer assessment students } & Metacognitive awareness pre & 40.33 & 6.59 & \\
\multirow{2}{*}{ Control group } & Metacognitive awareness post & 60.88 & 4.49 & \multirow{2}{*}{136.78} \\
& Metacognitive awareness pre & 38.98 & 8.65 & 0.001 \\
& Metacognitive awareness post & 45.55 & 8.04 & \\
\hline
\end{tabular}

TABLE 6: The results of covariance analysis for the metacognitive control variable of peer assessment students.

\begin{tabular}{lcccc}
\hline & Variable & Mean & Std. deviation & $F$ \\
\hline \multirow{2}{*}{ Peer assessment students } & Metacognitive control pre & 77.13 & 13.36 & \\
& Metacognitive control post & 122.40 & 8.07 & \multirow{2}{*}{146.23} \\
Control group & Metacognitive control pre & 76.08 & 20.65 & 0.001 \\
& Metacognitive control post & 97.73 & 12.17 & \\
\hline
\end{tabular}

and posttest autonomy questionnaire confirmed that there is a significant difference between pretest and posttest scores of learners. In other words, the self-assessment technique was seen as a helpful tool to help learners perform more autonomously in their writing performance. It was seen that learners showed more enthusiasm to complete their writing after receiving self-assessment instruction. Also, learners showed that self-assessment helps them learn about their strengths and weaknesses. In addition, learners' responses to the questionnaire as a posttest showed that they accept responsibility for their learning more than before. Overall, it was found that self-assessment is a helpful way to improve the autonomy of learners in completing their writings.

The findings of the present study were in line with findings from Adie [1]. According to them, self-assessment can improve the language proficiency of EFL learners. Despite this general similarity, it should be considered that this study investigated the impact of self-assessment on learners' autonomy only in writing skills, while the study just mentioned focused on language proficiency. In another study, Ashraf and Mahdinezhad [15] found that self-assessment influenced learners' autonomy more than peer assessment as it relates to speaking skills. Overall, the findings of the present study are similar to findings from the study by Ashraf and Mahdinezhad [15] who showed that self-assessment can improve autonomy. However, the findings can be regarded differently since the present study focused on writing skills, and the mentioned study focused on speaking skills. Almost in the same vein, Baleghizadeh and Masoun [10] showed that the self-assessment approach can improve the goal orientation and self-efficacy of learners. Their findings revealed that self-assessment improved the responsibility of learning among EFL learners. The findings of the present study are also parallel with the findings from the study by Khodadady and Khodabakhshzade [53]. Their studies confirmed that the self-assessment approach is a helpful way to increase learners' autonomy in writing performance. Another study in line with the findings of the present study which investigated the effect of self-assessment on the writing and accuracy of EFL learners was done by Birjandi and Siyyari [36]. They confirmed that self-assessment is a helpful technique to improve writing accuracy although its efficacy on autonomy was not investigated.

Also, in line with the finding of the present study, the evidence from the study by Liu and Brantmeier [13] showed that the writing accuracy of Chinese EFL learners improved using a self-assessment procedure. However, they just checked the impact of self-assessment on the writing accuracy of learners while the present study showed autonomy improvement in writing using self-assessment instruction. Furthermore, Sierra and Frodden [18] and Banister [2] showed that self-assessment discussion sessions and talking about self-assessing and evaluation of one's own self-assessment in the language learning process were effective in learner autonomy. They showed that affective factors, metacognition, and teacher role were the main components, which helped in learner autonomy. These results are similar to the results from the present study only ineffectiveness of self-assessment in language learning. Generally, the findings of the present study showed that self-assessment is an effective way to improve autonomy in language learning like most of the abovementioned studies. However, the findings are different from the abovementioned studies in that they focus on autonomy improvement in just writing skills through self-assessment instruction. From this perspective, it can be argued that participants' engagement in the assessment practices made them become more aware of the standards and criteria for producing better quality drafts, the 
awareness which encouraged them to exert more attention and effort to write better. Also, their participation in the assessment is likely to have given them a sense of responsibility and agency which fostered their motivation to improve their writing.

The second research question was on the impact of writing self-assessment in writing on Iranian EFL learners' metacognitive ability. Regarding the comparison of results from the pretest and posttest in the self-assessment group, it was found that self-assessment is a useful way to increase the metacognitive awareness of language learners. Data from questionnaires confirmed that learners' awareness regarding different components of metacognition was raised. It was seen that better learning, reflection on one's own learning process, and management of learning can be increased among learners. Learners showed that self-assessment was a helpful technique to raise their awareness of their writing skills. Also, it was found that different metacognitive strategies such as slowing down, focusing on meaning, using pictures and diagrams, focusing on meaning, and translating are effective ways to increase awareness of learners in writing skills. There were some similar studies that confirmed some of the above findings.

Siegesmund [20] and Shen et al. [12] argued that selfassessment is a reflection tool. In fact, learners use some criteria to assess their own performance and think critically about their learning process. Therefore, self-assessment is an effective way to increase metacognitive awareness and learn more metacognitive strategies in order to improve language learning. In line with the findings of the present study, Thirtle [48] found that self-assessment had a positive effect on the metacognitive awareness of learners. Participants in the posttest paid more attention to and had a further reflection on their tasks. Meanwhile, Thirtle's study showed that continuous feedback from oneself and reflection on one's own assignment for content and structure can be improved by self-assessing techniques.

The findings of this study are in line with the findings presented in the second language learning environment $[3,7,21]$. These studies emphasize self-assessment and its effect on learners' self-esteem, which leads to creativity and appropriate academic performance. The researchers found that participating in extracurricular activities such as watching movies, listening to stories, and summarizing conversations designed to boost learners' self-esteem had a positive effect on their test scores on language writing and reading skills. The fact was that devoting considerable time to in-class activities for assessment did not have the same positive effects on students' self-esteem as academic achievement. This confirms that the self-assessment activities were more successful than the assessment teacher's activities and tasks.

The third research question was to find out the effect of writing peer assessment on Iranian EFL learners' autonomy in an EFL context A comparison of pretest and posttest scores showed that the peer-assessment technique improves learner autonomy in writing skills. Regarding the posttest questionnaire, it was seen that learners in the peer-assessment group showed more independence in comparison to the pretest questionnaire. Also, it was seen that learners paid more attention to their strengths and weaknesses than before. In general, the difference in scores between pretest and posttest confirmed that peer assessment could be used as an effective way of teaching and learning writing skills and improve learners' autonomy in writing. In the following paragraph, the findings of the present study are compared with previous findings in the literature.

In a similar study, it was seen that peer assessment has an effective impact on the autonomy of learners in their speaking skills [15]. Also, they emphasized that peer assessment increased learner engagement in the learning process. Overall, the result from the present study overlaps in the positive impact of peer assessment in language learning skills. Findings from Birjandi and Siyyari [36] and Hornstra et al. [17] showed that using peer assessment improves the writing and accuracy of EFL learners. Similarly, de Brusa and Harutyunyan [16] indicated that peerassessment instruction improved the academic writing of university students. These studies emphasized that peer assessment is an effective way in English language teaching as the findings of the present study showed. Parallel with findings of the present study, Suludere [49] in an online environment investigated the relationship of peer assessment and learner autonomy on writing skills and indicated that peer assessment had a positive impact on the improvement of learner autonomy. It was also found that learners' awareness of their own learning, taking responsibility for their own learning, active engagement in the learning process, and evaluation of one's own learning improved, as findings of the present study showed.

The fourth research question addressed the impact of writing peer assessment on Iranian EFL learners' metacognitive awareness in an EFL context. As the comparison of the means of pretest and posttest questionnaires showed, there was a significant difference between posttest and pretest. As such, peer assessment had a positive impact on metacognitive awareness of the writing skills of language learners. Using peer-assessment techniques in writing skills showed that learners reflected on their own learning more and monitored their learning better. Also, learner awareness of cognitive strategies increased, and learners showed a more positive inclination to use different strategies such as translation, slowing down learning, and focusing on important information and meaning. According to results, it was found that peer assessment is generally a helpful way to increase language learners' metacognition awareness.

Regarding similarities of findings of the present study with previous studies in the literature, it should be mentioned that few research studies had focused on the impact of peer assessment on the metacognitive awareness of learners in their writing skills. However, some of the similarities are discussed now. Azizi et al. [23]; Winch [5]; Zarrinabadi et al. [19] examined the relationship between metacognitive awareness and writing proficiency. They found that evaluation was the most effective strategy in the writing proficiency of EFL learners. It was also found that learners used the monitoring strategy more than other strategies. In the findings of the present study, it was already mentioned that peer assessment helped learners become aware of the 
monitoring strategy after receiving treatment. In a study [22], examining the impact of metacognition on the writing skills of English learners, researchers found that metacognitive strategies improved the writing skills of secondary school students. Generally, these studies indicated that metacognitive strategy is a useful way of writing skills, and finding ways like peer assessment and self-assessment to improve metacognition could be effective in the improvement of different language skills.

\section{Conclusion}

This research aimed to investigate the impact of writing two important alternative assessment types, that is, self-assessment and peer assessment, on autonomy and metacognitive awareness of EFL learners. Peer assessment and self-assessment were instructed to see whether there is any significant difference in pretest and posttest results regarding autonomy and metacognitive awareness. Results from questionnaires in the pretest and posttest showed that both peer assessment and self-assessment can improve learner autonomy and metacognitive awareness in completing writing activities. This study has indicated that peer assessment and self-assessment are effective ways to be considered by other researchers and instructors in order to improve language learners' autonomy and metacognitive awareness. Although this study has shown that autonomy and metacognitive awareness of learners increased in their writing skills, it requires further quantitative as well as qualitative data to exactly examine what areas of writing can be improved simultaneously with the improvement of autonomy and metacognitive awareness.

6.1. Limitations. The study is not exempt from limitations. In this section first, some limitations of the study are presented which threatened the generalizability of the results: The number of participants in each group of the study was 40 which is not enough to generalize to larger population. Since this study has applied questionnaires to collect data, the number of participants limits the generalization of the results. Another limitation is related to the data collection method which is questionnaires. This method of data collection with a small number of participants affects the generalizability of data. It should be noted that using the convenience sampling method is another limitation of the study. In this study, participants were selected using convenient sampling.

6.2. Implications of the Study. The findings of the present research study might have some implications for researchers, instructors, language teachers, and language learners. According to the findings, it is possible to improve language teaching methods by using different types of alternative assessment, especially self-assessment and peer assessment, in order to direct learners toward more autonomous learning and help them learn various types of metacognition strategies for better learning. Also, findings can be used as guidance for those learners who need to learn a language in a specific period of time and learn in a selfstudy form.

Additionally, the findings may help syllabus designers, educators, and language instructors in designing both teaching materials and language tests since this study showed how peer assessment and self-assessment can improve autonomy and metacognition awareness of learners. In designing course books and materials, it would be worthwhile to integrate exercises and activities that help teachers and learners improve autonomy and metacognitive awareness.

6.3. Suggestions for Further Research. The present study attempted to illuminate the impact of self-assessment and peer assessment on the improvement of autonomy and metacognitive awareness in a language learning context. Despite the findings from the study, there are still some challenging issues that can be considered in the future research.

First of all, this study exploited both female and male participants. However, differences in their improvement in autonomy and metacognitive awareness through peer assessment and self-assessment were not tested. Future research can consider this issue. Secondly, two experimental groups in the present study have participated but their impact was tested on the dependent variables separately. So, it would be valuable to compare the impact of two different alternative assessments and find more ways to improve their role in language teaching and learning. The next remarkable point is the comparison of results from autonomy and metacognitive awareness. Future research may compare the improvement of autonomy and metacognitive awareness using peer-assessment and self-assessment approaches. Last but not least is that scoring of writings and comparison of the scores with questionnaire results might help gain more valuable results on the impact of self-assessment and peer assessment on autonomy and metacognitive awareness of EFL learners in writing skills.

\section{Data Availability}

The datasets used and/or analyzed during the current study are available from the corresponding author on reasonable request (cyrosizadpanah@yahoo.com).

\section{Conflicts of Interest}

The authors declare that they have no conflicts of interest.

\section{References}

[1] L. Adie, B. Addison, and B. Lingard, "Assessment and learning: an in-depth analysis of change in one school's assessment culture," Oxford Review of Education, vol. 47, no. 3, pp. 404-422, 2021.

[2] C. Banister, "Exploring peer feedback processes and peer feedback meta-dialogues with learners of academic and business English,” Language Teaching Research, 2020. 
[3] S. Khamlichi and A. Chkirbane, "The impact of attitudes towards assessment on learning strategies: the case of young EFL learners in Morocco," Education, vol. 3-13, pp. 1-14, 2021.

[4] C. S. Taylor and S. B. Nolen, "Classroom assessment and diversity," Encyclopedia of Diversity in Education, vol. 1, pp. 389-393, 2012, https://www.pearson.com/us/highereducation/product/Taylor-Classroom-Assessment/ 9780130974273.htmlnglish.

[5] C. Winch, "Autonomy as an educational aim," in The RoutledgeFalmer Reader in Philosophy of Education, pp. 6573, Routledge, Oxfordshire, UK, 2021.

[6] T. Ladenika, "Engaging the pedagogic potential of WP learner autonomy in HE: a case study on the design and exploration of an autonomous learning construct, and its application to practice," Doctoral dissertation, The Open University, London, UK, 2021.

[7] M. Podsiad and B. Havard, Faculty Acceptance of the Peer Assessment Collaboration Evaluation Tool: A Quantitative Study, vol. 3, pp. 1-27, Educational Technology Research and Development, New York, NY, USA, 2020.

[8] K. J. Topping, E. F. Smith, I. Swanson, and E. Elliot, "Formative peer assessment of academic writing between postgraduate students," Assessment \& Evaluation in Higher Education, vol. 25, no. 2, pp. 149-169, 2000.

[9] F. Murase, "Measuring language learner autonomy: problems and possibilities," in Assessment and Autonomy in Language Learning, pp. 35-63, Palgrave Macmillan, London, UK, 2015.

[10] S. Baleghizadeh and A. Masoun, "The effect of self-assessment on EFL learners' goal orientation," Iranian Journal of Applied Linguistics, vol. 17, no. 1, pp. 25-48, 2014, https://ijal.khu.ac. ir/article-1-2025-en.pdf.

[11] Z. Mohamadi, "Comparative effect of online summative and formative assessment on EFL student writing ability," Studies In Educational Evaluation, vol. 59, pp. 29-40, 2018.

[12] B. Shen, B. Bai, and W. Xue, "The effects of peer assessment on learner autonomy: an empirical study in a Chinese college English writing class," Studies In Educational Evaluation, vol. 11, no. 64, p. 74, 2020.

[13] H. Liu and C. Brantmeier, “"I know English": self-assessment of foreign language reading and writing abilities among young Chinese learners of English," System, vol. 80, pp. 60-72, 2019.

[14] A. Karami and A. Rezaei, "An overview of peer-assessment: the benefits and importance," Journal for the Study of English Linguistics, vol. 3, no. 1, pp. 93-100, 2015.

[15] H. Ashraf and M. Mahdinezhad, "The role of peer-assessment versus self-assessment in promoting autonomy in language use: a Case of EFL Learners," Iranian Journal of Language Testing, vol. 5, no. 2, pp. 110-120, 2015, https://pdfs. semanticscholar.org/a7f4/ 764fc0bb730681690ab628f544a2a78aebc0.pdf.

[16] M. F. P. de Brusa and L. Harutyunyan, "Peer review: a tool to enhance the quality of academic written productions," English Language Teaching, vol. 12, no. 5, pp. 30-39, 2019.

[17] L. Hornstra, K. Stroet, and D. Weijers, "Profiles of teachers' need-support: how do autonomy support, structure, and involvement cohere and predict motivation and learning outcomes?” Teaching and Teacher Education, vol. 99, p. 103, 2021.

[18] A. M. Sierra and C. Frodden, "Promoting student autonomy through self-assessment and learning strategies," HOW Journal, vol. 10, no. 1, pp. 133-166, 2017, https:// howjournalcolombia.org/index.php/how/article/view/377.

[19] N. Zarrinabadi, N. M. Lou, and M. Shirzad, "Autonomy support predicts language mindsets: implications for developing communicative competence and willingness to communicate in EFL classrooms," Learning and Individual Differences, vol. 86, p. 101, 2021.

[20] A. Siegesmund, "Using self-assessment to develop metacognition and self-regulated learners," FEMS Microbiology Letters, vol. 364, no. 11, 2017.

[21] W. Wanna and A. Paulos, "Beliefs and practices of learner autonomy in developing English language skills: the case of dilla university students' learning experiences outside the classroom," Ethiopian Journal of Education, vol. 41, no. 1, pp. 45-73, 2021.

[22] T. M. Al-Jarrah, N. Mansour, and R. Ab Rashid, "The impact of metacognitive strategies on jordanian EFL learners' writing performance," International Journal of English Linguistics, vol. 8, no. 6, pp. 328-339, 2018.

[23] M. Azizi, A. Nemati, and N. Estahbanati, "Meta-cognitive awareness of writing strategy use among Iranian EFL learners and its impact on their writing performance," International Journal of English Language \& Translation Studies, vol. 5, no. 1, pp. 42-51, 2017, http://www.eltsjournal.org/archive/ value5issue1/6-5-1-17.pdf.

[24] L. Schwartz, I. Adler, N. Madjar, and M. Zion, "Rising to the challenge: the effect of individual and social metacognitive scaffolds on students' expressions of autonomy and competence throughout an inquiry process," Journal of Science Education and Technology, vol. 30, pp. 582-593, 2021.

[25] T. Q. Tran and T. M. Duong, "EFL learners' perceptions of factors influencing learner autonomy development," Kasetsart Journal of Social Sciences, 2018.

[26] P. Birjandi and M. Siyyari, "Self-assessment and peer-assessment: a comparative study of their effect on writing performance and rating accuracy," Iranian Journal of Applied Linguistics, vol. 13, no. 1, pp. 23-45, 2011.

[27] J. Fathi, S. Mohebiniya, and S. Nourzadeh, "Enhancing second language writing self-regulation through self-assessment and peer-assessment: a Case of Iranian EFL Learners," International Journal of Applied Linguistics \& English Literature, vol. 8, no. 3, pp. 110-117, 2019.

[28] J. Fathi and M. Shirazizadeh, "Fostering self-regulated learning of Iranian EFL students: an investigation of the effect of self and peer assessment in L2 writing," Foreign Language Research Journal, vol. 9, no. 1, pp. 123-146, 2019.

[29] M. Ghahfarokhi and M. Tavakoli, "The effect of technologymediated reading comprehension tasks on autonomy and metacognitive strategy use by Iranian EFL intermediate learners," Journal of Modern Research in English Language Studies, vol. 7, no. 3, pp. 45-69, 2020.

[30] H. R. Iraji, M. J. Enayat, and M. Momeni, "The effects of selfand peer-assessment on Iranian EFL learners' argumentative writing performance," Theory and Practice in Language Studies, vol. 6, no. 4, pp. 716-722, 2016.

[31] S. Mazloomi and M. Khabiri, "The impact of self-assessment on language learners' writing skill," Innovations in Education \& Teaching International, vol. 55, no. 1, pp. 91-100, 2018.

[32] J. C. Richards and R. W. Schmidt, Longman Dictionary of Language Teaching and Applied Linguistics, Routledge, Oxfordshire, UK, 2013.

[33] N. F. Liu and D. Carless, "Peer feedback: the learning element of peer assessment," Teaching in Higher Education, vol. 11, no. 3, pp. 279-290, 2006.

[34] N. Falchikov, "Learning Together; Peer Tutoring in Higher Education," in Routledge-Falmer, London, UK, 2001.

[35] M. Oscarson and B. M. Apelgren, "Mapping language teachers' conceptions of student assessment procedures in 
relation to grading: a two-stage empirical inquiry," System, vol. 39, no. 1, pp. 2-16, 2011.

[36] P. Birjandi and M. Siyyari, "Self-assessment and peer-assessment: a comparative study of their effect on writing performance and rating accuracy," Iranian Journal of Applied Linguistics, vol. 13, 2010, https://ijal.khu.ac.ir/browse.php?a_ $\mathrm{id}=44 \&$ slc_lang $=$ fa\&sid $=1 \& \mathrm{ftxt}=1$.

[37] L. Plakans, "Then and now: themes in language assessment research," Language Education \& Assessment, vol. 1, no. 1, pp. 3-8, 2018.

[38] A. Antonietti and M. F. Mancini, "Relationships between metacognition, self-efficacy and self-regulation in learning," Educational, Cultural and Psychological Journal, vol. 7, no. A, pp. 114-141, 2013.

[39] S. Cotterall and G. Murray, "Enhancing metacognitive knowledge: structure, affordances and self," System, vol. 37, no. 1, pp. 34-45, 2009.

[40] G. Schraw and R. S. Dennison, "Assessing metacognitive awareness," Contemporary Educational Psychology, vol. 19, no. 4, pp. 460-475, 1994.

[41] R. Goctu, "Metacognitive strategies in academic writing," Journal of Education in Black Sea Region, vol. 2, no. 2, pp. 82-96, 2017.

[42] M. Artar and İ. Gönüllü, "The impact of metacognition training on metacognitive awareness of medical students," 2014, https://dergipark.org.tr/en/download/article-file/63392.

[43] M. Farahian, "Developing and validating a metacognitive writing questionnaire for EFL learners," Issues in Educational Research, vol. 27 , no. 4, p. 736,2017 , http://www.iier.org.au/ iier27/farahian.pdf.

[44] M. Rahimi and M. Katal, "Metacognitive strategies awareness and success in learning English as a foreign language: an overview," Procedia-Social and Behavioral Sciences, vol. 31, pp. 73-81, 2012.

[45] Y. Doğan and M. Tuncer, "Effect of metacognitive awareness on achievement in foreign language learning," Dynamic Assessment, https://www.asha.org/practice/multicultural/ issues/Dynamic-Assessment/, 2017.

[46] C. C. M. Goh, C. Goh, and A. Burns, Teaching Speaking, Ernst Klett Sprachen, Stuttgart, Germany, 2012, https://www.academia. edu/8628014/Teaching_Speaking_A_Holistic_Approach.

[47] H. Gholami, "Self-assessment and learner autonomy," Theory and Practice in Language Studies, vol. 6, no. 1, pp. 46-51, 2016.

[48] S. Thirtle, "Self-assessment in learning: the relationship between active feedback strategies and metacognitive development," Teaching in lifelong learning: A Journal to Inform and Improve Practice, vol. 6, no. 1, pp. 5-19, 2014, http://eprints. hud.ac.uk/21331/1/612.pdf.

[49] H. N. Suludere, "The online peer feedback and learner autonomy in English as a foreign language writing classes," Bachelor's thesis, Università Ca'Foscari Venezia, Venice, Italy, 2012.

[50] W. S. Fowler and N. Coe, "Nelson Proficiency Tests," Butler \& Tanner Ltd., London, UK, 1976.

[51] M. S. Terlecki and A. McMahon, "A call for metacognitive intervention: improvements due to curricular programming in leadership," Journal of Leadership Education, vol. 17, no. 4, pp. 115-135, 2018.

[52] W. Zhang, D. Su, and M. Liu, "Personality traits, motivation and Foreign language attainment," Journal of Language Teaching and Research, vol. 4, no. 1, pp. 58-66, 2004.

[53] E. Khodadady and H. Khodabakhshzade, "The effect of portfolio and self-assessment on writing ability and autonomy," Journal of Language Teaching and Research, vol. 3, no. 3, p. 518, 2012. 